\section{Pore Canals in the Cuticle of Hypoderma bovis (Diptera)}

THe pore canals of the larval cuticle of Hypoderma bovis are extremely conspicuous. When the cuticle is treated with saturated potassium hydroxide solution followed by iodine and sulphuric acid ${ }^{1}$, they are seen to be occupied by helical strands of chitosan $2-3 \mu$ thick, which give a much stronger reaction than the remainder of the cuticle. The helical nature of the canals is readily seen in a horizontal optical section. On changing the plane of focus the optical section of the canal clearly described a circular path. The diameter of the helix is about $5 \mu$ and in vertical sections its pitch is seen to be about $6 \mu$. There is no relation between the pitch of the helix and the spacing of the laminæ of the cuticle. Between 5 and 6 laminæ are transversed by one complete turn of the helix (Fig. 1).

In electron microscope investigations on the pore canals of Tenebrio, Calpodes, Galleria and the honey bee, Locke $^{2}$ found a correspondence between the pitch of an apparent helix and the spacing of the laminæ, and since the distribution of the canals in tangential section did not conform to the pattern expected for a random distribution of helical pore canals he concluded that the canals are not in fact helical, but pursue an undulating course from lamina to lamina. It is interesting, however, that the pattern seen by Locke in tangential sections resembles that seen by Drach ${ }^{3}$ in similar sections of the cuticle of the crab Carcinides in which, as in Hypoderma, the canals appeared to be helical, rotating as the plane of horizontal section was changed.

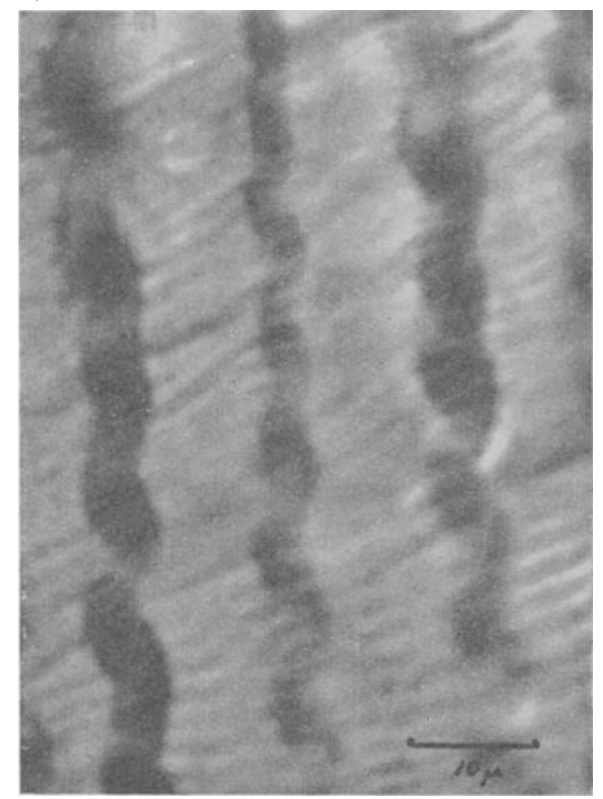

Fig. 1. The pore canals of Hypoderma bovis as seen after the chitosan reaction

These observations on the very large and readily observed canals of Hypoderma are clearly in agreement with the opinion that the arthropod pore canal is helical ${ }^{4}$, and contrast with the condition reported by Locke in the insects he examined.

I thank Prof. E. A. Vincent for the photograph of the pore canals and Mr. J. C. Wood for living Hypoderma larvæ.

Department of Zoology,

University of Manchester.

${ }^{1}$ Campbell, F. L., Ann. Ent. Soc. Amer., 22, 401 (1929).

${ }^{2}$ Locke, M., J. Biophys. Biochem. Cytol., 10, 589 (1961).

${ }^{3}$ Drach, P., Ann. Inst. Oceanogr., 19, 103 (1939).

4 Richards, A. G., The Integument of Arthropods (University of Minnesota Press, 1951).
Prds,

\section{CYTOLOGY}

\section{Glutaric Acid Dialdehyde; a Routine Fixative for Central Nervous System Electron Microscopy}

THE central nervous system of mammals presents special problems to the electron microscopist, because of its relative inaccessibility, and the fact that the brain is by no means a uniform organ but is composed of sub-units, about the structure or function of which we know little, and because of the extremely soft nature of fresh cerebral tissue. Although the most accessible area, the cerebral cortex, has beon investigated extensively, it still remains to investigate the less superficial sub-units in detail. Attempts to dissect out such deeper structures from slices of soft, fresh brain, and then to cut these into smaller pieces for adequate fixation in osmium tetroxide, are often attended by disruption of structural organization resulting largely from mechanical manipulation-dark neurones are familiar to both light and electron microscopists.

The slow penetration of buffered osmium tetroxide during the first $2 \mathrm{~h}$ results in only superficial fixation when thin coronal slices of fresh brain are completely immersed in solutions of the fixative. The reduction of osmium tetroxide during fixation produces a diffuse blackening of these slices, so that all detail of deeper structuresthe contrast between grey and white matter so important in gross anatomical localization-is obscured. Likewise, attempts to fix the central nervous system in situ by perfusing osium tetroxide through the vascular system produce excellent tissue preservation in skilled hands ${ }^{1}$, but again, due to diffuse blackening of the fixed organ, specific anatomical localization cannot be readily performed.

Osmium tetroxide, though an excellent fixative, destroys enzymatic activity very quickly, and for this reason less-destructive fixatives such as formalin, acrolein and glutaric acid dialdehyde ${ }^{2-4}$ have been introduced in an attempt to preserve fine tissue structure as well as enzymatic activity. We have found that glutaric acid dialdehyde (glutaraldehyde) used as a routine primary fixing agent for the central nervous system, followed by postfixation in osmium tetroxide, gives very adequate fine structural preservation of whole coronal slices of the brain of the mouse and the Syrian hamster.

We have used a 6.5 per cent solution of glutaraldehyde buffered at $p \mathrm{H} 7.4$ with either $0 \cdot 1 \mathrm{M}$ phosphate or $0.1 \mathrm{M}$ cacodylate buffer, though the phosphate buffer (Sorensen) has been found to be the most stable. Excellent tissue preservation was obtained both by perfusion via the left ventricle and ascending aorta, and by immersion of whole coronal slices, $2-4 \mathrm{~mm}$ in thickness, in buffered glutaraldehyde. We prefer the immersion method, because the majority of small vessels are greatly distended by perfusion, making their structure and their relationship to the neighbouring parenchyma difficult to interpret.

Fixation was allowed to proceed for $1.5 \mathrm{~h}$ at $4^{\circ} \mathrm{C}$, then the coronal slices, after preliminary washing in $0.2 \mathrm{M}$ sucrose in either $0.1 \mathrm{M}$ phosphate or $0.1 \mathrm{M}$ cacodylate buffer at $p \mathrm{H} 7 \cdot 4$, were examined under a dissecting microscope. Glutaraldehyde caused a slight yellowing of all brain areas, but did not interfere with gross anatomical localization. Small blocks could then be removed at leisure with a sharp razor blade from any selected area, and shaped for later orientation when embedding. The selected blocks were then washed further in the sucrose phosphate or sucrose cacodylate buffer for $24-48 \mathrm{~h}$ before post-fixation for $1.5 \mathrm{~h}$ at $4^{\circ} \mathrm{C}$ in 1 per cent osmium tetroxide buffered in veronal acetate. We have used Vestopal ' $W$ ' as an embedding medium, but other plastics'Araldite' and 'Epon', etc.--may also be used. However, as indicated by Sabatini et al.4, mixtures of methyl and butyl methacrylate were not suitable, as extensive sublimation 